\title{
New Diagnostic Algorithm to Asymptomatic Coronary Artery Disease in Patients with Lower Peripheral Artery Disease
}

\author{
Yasemin Saglam, $M D^{1}$ (D) and Ersin Saricam, $M D^{2^{*}}$ \\ ${ }^{1}$ Medicana International Ankara Hospital, Guven Hospital, Turkey \\ ${ }^{2}$ Medicana International Ankara Hospital, Atilim University, Turkey
}

*Corresponding author: Ersin Saricam, Medicana Ankara Hospital, Atilim University, Cardiology Clinic, Sogutozu District, 2165 St. No: 6 Sogutozu, Turkey, Tel: +905324066440 ; Fax: +903122203170

\begin{abstract}
Purpose: To suggest a risk index to prediction of coronary artery disease severity by examining lower extremity arterial regions in the patients with lower extremity peripheral artery disease.

Patients and methods: We retrospectively examined 4255 patients who experienced coronary angiography between September 2015 and January 2020. Medicana International Ankara Hospital Ethics Committee accepted the study schedule [Numbered: 2017/1]. Of the patients, 400 patients underwent both coronary angiography and lower extremity angiography because of peripheral artery disease symptoms. The odds ratios of coronary artery disease according to risk factors have been examined. Angiographically, lower extremity arteries were divided into three groups. The decision tree created using the ChiSquare Automatic Interaction Detection (CHAID) method was used to estimate relationship between segmental arterial regions in peripheral artery disease and severity of coronary artery disease.
\end{abstract}

Results: The odds ratios of the peripheral artery disease with diabetes mellitus to those without diabetes mellitus was found to be $1 / 0.269=3.717$. Both superficial femoral artery involvement increased by $88 \%$ the possibility of coronary artery disease. In coronary involvement, the most power predictor was mid-superficial femoral artery disease. Moreover, the involvement of both the mid superficial femoral artery increased the possibility of left main coronary artery disease by $42.1 \%$.

Conclusion: Mid-superficial femoral artery blockage may be a strong predictor of coronary artery disease. The involvement of both the mid-superficial femoral artery increased significantly the possibility of left main coronary artery disease. The diabetic patients with mid-superficial femoral artery involvement should be evaluated for severe coronary artery disease.

\section{Keywords}

Coronary artery disease, Risk index, Peripheral arterial disease

\author{
Abbreviations \\ CAD: Coronary Artery Disease; PAD: Peripheral Artery \\ Disease; OR: Odds Ratio
}

\section{Introduction}

Atherosclerosis, a progressive disorder, may concurrently disturb numerous arterial region [1]. Concomitant atherosclerotic disease of different vascular territories foreshows an adverse prognosis [2]. To know the associating site of involvement of one vascular bed may be important for clinicians (for example, peripheral artery involvement associated with serious coronary artery disease, and left main coronary artery involvement). While atherosclerosis involves the aortoiliac segment in the young and non-diabetic patients commonly, differences in lesion distribution become increasingly apparent with age [3]. TASC II Working Group stated that the place and morphology of the lower extremity arterial disease must be characterized prior to perform any revascularization to foresee most suitable intervention [4].

The prevalence of coronary artery disease (CAD) in patients with peripheral arterial disease (PAD) ranges between 46 and $71 \%[5,6]$. Because of reduced daily activity and silent ischemia, cardiac symptoms may be absent in patients with lower extremity artery illness. Moreover, PAD may predict future cardiovascular

Citation: Saglam Y, Saricam E (2021) New Diagnostic Algorithm to Asymptomatic Coronary Artery Disease in Patients with Lower Peripheral Artery Disease. Clin Med Rev Case Rep 8:355. doi. org/10.23937/2378-3656/1410355

Accepted: June 28, 2021: Published: June 30, 2021

Copyright: (C) 2021 Saglam Y, et al. This is an open-access article distributed under the terms of the Creative Commons Attribution License, which permits unrestricted use, distribution, and reproduction in any medium, provided the original author and source are credited. 
conditions, such as myocardial infarction and death [7]. Therefore, the presence of PAD may be one of the critical factors predicting future cardiac events. However, the method of how CAD can be precisely predicted in lower extremity arterial disease is unclear. Therefore, we aimed to find a risk index to prediction of CAD by examining different segmental arterial regions in the patients with lower extremity peripheral artery disease (PAD).

\section{Material and Methods}

We retrospectively examined 4255 patients underwent coronary angiography between September 2015 and January 2020. Medicana International Ankara Hospital Ethics Committee accepted the study schedule [Numbered: 2017/2]. We watched out to Declaration of Helsinki principles. Of the patients, 400 patients underwent both coronary angiography and lower extremity angiography due to peripheral artery disease.

A diagnostic point of PAD was angiographically significant narrowing $(\geq 50 \%)$ in at least one artery of the lower extremities connected with intermittent claudication or critical limb ischemia according to the Fontaine classification [8]. The ankle-brachial index (ABI) all of patients was $\leq 0.90$. The generality of the patients was in the New York Heart Association (NYHA) Functional Class II.

To create a risk index to coronary artery disease, angiographically, lower extremity arteries were separated into three groups including 1) Iliac arteries, 2) Femoral arteries (main femoral arteries, superficial femoral arteries), and 3) Popliteal-tibio-peroneal arteries.

In this cohort, because of having at least one coronary risk factor despite asymptomatic, concurrent coronary angiography were also performed. The indication of coronary angiography in 400 patients was accepted as one coronary risk factor (hypertension, diabetes mellitus, and hyperlipidemia) plus peripheral artery disease evidence.

In coronary angiography, coronary artery disease was accepted at least $50 \%$ narrowing in coronary arteries. Side branch artery involvements with $<2 \mathrm{~mm}$ diameter were excluded. The patients had no $Q$ wave or QS pattern in their electrocardiograms. The coronary artery involvement regions were divided into left main coronary artery disease (LMCA), left anterior descending (LAD), left circumflex $(C x)$, right coronary artery disease (RCA).

The exclusion conditions were CAD history such as previous coronary angiography, percutaneous coronary intervention, coronary bypass surgery, thromboembolic events or non-atherosclerotic lesions (Buerger's disease).

\section{Definition of the risk index of CAD}

In coronary arteries, at least $50 \%$ narrowing was accepted as positive risk index.
The CAD was described as non-obstructive $C A D$, and obstructive CAD. The extent of the disease was reported as, single vessel disease (SVD), double vessel disease (DVD), triple vessel disease (TVD) and LMCA.

\section{Procedure}

Lower extremity angiography was performed by the pump with anteroposterior views of the aorta (Siemens, Axiom 2004 Artis, Germany). The renal arteries, distal abdominal aorta, iliac arteries, femoral arteries, and distal arteries were checked in LEA. Selective coronary angiography was, then, performed using standard Judkins catheters. The left main vessel and origins of both the LAD and the Cx coronary arteries were visualized in the orthogonal planes using digital imaging system (Siemens, Axiom 2004 Artis, Germany) and cineangiographic films.

Cineangiographic films were reviewed independently by two investigators. A diagnostic criterion of CAD was angiographically significant narrowing $(\geq 50 \%)$. The patients were hydrated with isotonic fluid $(0.9 \%)$ in addition to oral acetylcysteine (600 mg twice daily). Renal functions of the patients during discharge were normal.

\section{Risk factors}

Considering the risk factors, hypertension was recognized by a history of anti-hypertensive medicine use. Diabetes mellitus was characterized by the patient's using an oral hypoglycemic agent, or insulin, and/or the patient's having a fasting blood glucose level $\geq 126 \mathrm{mg} /$ $\mathrm{dL}$ or glycosylated hemoglobin $\geq 6.5 \%$. Dyslipidemia was identified by a history of statin use, or having a lowdensity lipoprotein (LDL) cholesterol level $>100 \mathrm{mg} / \mathrm{dL}$.

\section{Statistical analysis}

Statistical analysis was performed using SPSS Inc. v17.0 for Windows (SPSS Inc., Chicago, IL, USA). Descriptive data were expressed in mean and range. While categorical variables were analyzed using the chisquare test, continuous variables were analyzed using the student t-test. In the decision tree, the Chi-Square Automatic Interaction Detection (CHAID) method was been used. A $p$ value of $<0.05$ was considered statistically significant.

\section{Results}

Demographic and clinical characteristics of the patients are shown in Table 1. The mean age was 65.54 \pm 6.3 (range: 51 to 80 ) years. The rate of CAD in PAD patients was $66 \%$. The regions affected by coronary artery involvement were LAD (29\%), CX (13\%), right coronary artery (RCA) (5\%), left main coronary artery (LMCA) (18\%), LAD proximal and RCA or Cx (2\%), threevessel CAD (2\%), RCA and Cx (2\%), and non-critical or normal coronary artery (34\%). 
Table 1: Baseline clinical characteristic in patients with and without coronary artery disease.

\begin{tabular}{|c|c|c|c|}
\hline Variable & Value & Frequencies & Percent \\
\hline \multirow[t]{2}{*}{ Sex } & Female & 92 & 23.0 \\
\hline & Male & 308 & 77.0 \\
\hline \multirow[t]{2}{*}{ Age } & No & & $66.18 \pm 5.94$ \\
\hline & Yes & $65.21 \pm 6.44$ & \\
\hline \multirow[t]{2}{*}{ Hypertension } & No & 220 & 55.0 \\
\hline & Yes & 180 & 45.0 \\
\hline \multirow[t]{2}{*}{ Diabetes } & No & 144 & 36.0 \\
\hline & Yes & 256 & 64.0 \\
\hline \multirow[t]{2}{*}{ Hyperlipidemia } & No & 312 & 78.0 \\
\hline & Yes & 88 & 22.0 \\
\hline \multirow[t]{2}{*}{ Smoking } & No & 128 & 32.0 \\
\hline & Yes & 272 & 68.0 \\
\hline \multirow{8}{*}{$\begin{array}{l}\text { Coronary artery involvement } \\
\text { region }\end{array}$} & SVD (LAD) & 116 & 29.0 \\
\hline & SVD (Cx) & 52 & 13.0 \\
\hline & SVD (RCA) & 20 & 5.0 \\
\hline & Left main disease (LMCA) & 72 & 18.0 \\
\hline & DVD (LAD prox/osteal with RCA or Cx involvement & 8 & 2.0 \\
\hline & DVD (RCA and Cx) & 8 & 2.0 \\
\hline & TVD (Three-vessel disease) & 8 & 2.0 \\
\hline & Non-obstructive, including normal coronary & 136 & 34.0 \\
\hline \multirow[t]{3}{*}{ Fontaine Class } & Class 2 & 8 & 2.0 \\
\hline & Class 3 & 384 & 96.0 \\
\hline & Class 4 & 8 & 2.0 \\
\hline \multirow[t]{2}{*}{ Puncture region } & Femoral & 280 & 70.0 \\
\hline & Radial & 120 & 30.0 \\
\hline \multirow[t]{3}{*}{ Coronary therapy } & Medical & 136 & 34.0 \\
\hline & $\mathrm{PCl}$ & 156 & 39.0 \\
\hline & Surgery & 108 & 27.0 \\
\hline
\end{tabular}

SVD: Single Vessel Disease; DVD: Double Vessel disease; TVD: Tripple Vessel Disease

The odds ratios (OR) of CAD according to risk factors have been examined. Diabetes mellitus was a strong predictor of CAD $(p<0.01)$. The OR of the patients with diabetes mellitus to those without diabetes mellitus was found to be $1 / 0.269=3.717$, indicating that the existence of the CAD in the patients with diabetes mellitus was 3.717 times higher. In addition, the presence of hypertension and hyperlipidemia had a significant effect on the CAD development $(p<0.05)$. The OR values were found to be 0.70 for hypertension and 1.75 for hyperlipidemia.

Lower extremity arteries were divided into three groups including iliac arteries, femoral arteries, and popliteal-tibioperoneal arteries, according to the most involved regions.

There was no significant relationship among the involvement of the right iliac artery and CAD $(p>0.05)$. However, a significant association among the left iliac artery and CAD was observed $(p<0.01)$. Although there was a significant association between the involvement of right/left femoral artery and CAD $(p<0.01)$, no important relationship between the involvement of the right/left popliteal-tibioperoneal arteries and CAD was found $(p>0.05)$.

Remarkably, the rate of CAD was higher in the patients with affected femoral arteries. Among the regions of the femoral arteries, superficial femoral arteries were affected more than the others. Therefore, for a detailed analysis of the region, superficial femoral artery segments were examined in three subgroups as ostial-proximal superficial femoral artery, midsuperficial femoral artery (inside the canal of Hunter), and distal superficial femoral artery (after the canal of Hunter).

The association between the right ostial-proximal superficial femoral artery and CAD was insignificant $(p>$ $0.05)$, while there was important relationship between the right mid-superficial femoral artery and CAD ( $p$ $<0.05$ ). $93 \%$ of the patients with right mid-superficial femoral artery had CAD, while $60.5 \%$ of the patients 
without right mid-superficial femoral artery had CAD.

In addition, there was no significant association among the left ostial-proximal superficial femoral artery and CAD ( $p>0.05)$. However, there was a significant association between the left mid-superficial femoral artery and CAD ( $p<0.05)$. 91.9\% of the patients with left mid-superficial femoral artery had CAD, while $71.4 \%$ of the patients without left mid-superficial femoral artery had CAD. The association between both right and left distal superficial femoral artery and CAD was not significant $(p>0.05)$, indicating that mid-superficial femoral arteries occlusion may be a strong predictor of asymptomatic CAD.

Furthermore, there was a significant association between the unilateral or bilateral superficial femoral artery and CAD $(p<0.05) .23 .5 \%$ of the patients without femoral artery involvement had CAD, while $72.7 \%$ of the patients with unilateral artery involvement had CAD and $78.6 \%$ of the patients with bilateral artery involvement had CAD (Table 2).

Table 2: Possibility coronary artery disease and locations of lower extremity PAD lesions.

\begin{tabular}{|c|c|c|c|c|c|c|c|}
\hline \multirow[t]{2}{*}{ Variable } & \multirow[t]{2}{*}{ Level } & & \multicolumn{2}{|c|}{ CAD } & \multirow[b]{2}{*}{ Total } & \multirow[b]{2}{*}{$x^{2}$} & \multirow[b]{2}{*}{$\mathbf{P}$} \\
\hline & & & No & Yes & & & \\
\hline \multirow[t]{4}{*}{ Right iliac artery } & \multirow[t]{2}{*}{ No } & f & 100 & 204 & 304 & \multirow[t]{4}{*}{0.69} & \multirow[t]{4}{*}{0.41} \\
\hline & & $\%$ & 32.9 & 67.1 & 100.0 & & \\
\hline & \multirow[t]{2}{*}{ Yes } & $f$ & 36 & 60 & 96 & & \\
\hline & & $\%$ & 37.5 & 62.5 & 100.0 & & \\
\hline \multirow[t]{4}{*}{ Left iliac artery } & \multirow[t]{2}{*}{ No } & $f$ & 124 & 204 & 328 & \multirow[t]{4}{*}{$11.76^{* *}$} & \multirow[t]{4}{*}{0.00} \\
\hline & & $\%$ & 37.8 & 62.2 & 100.0 & & \\
\hline & \multirow[t]{2}{*}{ Yes } & $f$ & 12 & 60 & 72 & & \\
\hline & & $\%$ & 16.7 & 83.3 & 100.0 & & \\
\hline \multirow[t]{4}{*}{ Right femoral artery } & \multirow[t]{2}{*}{ No } & $f$ & 68 & 76 & 144 & \multirow[t]{4}{*}{$17.53^{\star *}$} & \multirow[t]{4}{*}{0.00} \\
\hline & & $\%$ & 47.2 & 52.8 & 100.0 & & \\
\hline & \multirow[t]{2}{*}{ Yes } & $f$ & 68 & 188 & 256 & & \\
\hline & & $\%$ & 26.6 & 73.4 & 100.0 & & \\
\hline \multirow[t]{4}{*}{ Left femoral artery } & \multirow[t]{2}{*}{ No } & f & 88 & 140 & 228 & \multirow[t]{4}{*}{$4.99^{*}$} & \multirow[t]{4}{*}{0.03} \\
\hline & & $\%$ & 38.6 & 61.4 & 100.0 & & \\
\hline & \multirow[t]{2}{*}{ Yes } & $f$ & 48 & 124 & 172 & & \\
\hline & & $\%$ & 27.9 & 72.1 & 100.0 & & \\
\hline Right popliteal-tibioperoneal & No & $\mathrm{f}$ & 112 & 236 & 348 & 3.93 & 0.05 \\
\hline & & $\%$ & 32.2 & 67.8 & 100.0 & & \\
\hline & Yes & f & 24 & 28 & 52 & & \\
\hline & & $\%$ & 46.2 & 53.8 & 100.0 & & \\
\hline Left popliteal-tibioperoneal & No & f & 116 & 236 & 228 & 1.43 & 0.23 \\
\hline & & $\%$ & 33.0 & 67.0 & 100.0 & & \\
\hline & Yes & f & 20 & 28 & 48 & & \\
\hline & & $\%$ & 41.7 & 58.3 & 100.0 & & \\
\hline Right prox. superficial & No & $f$ & 116 & 232 & 348 & 0.53 & 0.47 \\
\hline & & $\%$ & 33.3 & 66.7 & 100.0 & & \\
\hline & Yes & f & 20 & 32 & 52 & & \\
\hline & & $\%$ & 38.5 & 61.5 & 100.0 & & \\
\hline Left superficial femoral & No & $f$ & 124 & 244 & 368 & 0.19 & 0.66 \\
\hline & & $\%$ & 33.7 & 66.3 & 100.0 & & \\
\hline & Yes & f & 12 & 20 & 32 & & \\
\hline & & $\%$ & 37.5 & 62.5 & 100.0 & & \\
\hline Right mid superficial femoral & No & f & 88 & 100 & 188 & $25.93^{* *}$ & 0.00 \\
\hline & & $\%$ & 46.8 & 53.2 & 100.0 & & \\
\hline & Yes & $f$ & 48 & 164 & 212 & & \\
\hline & & $\%$ & 22.6 & 77.4 & 100.0 & & \\
\hline
\end{tabular}




\begin{tabular}{|c|c|c|c|c|c|c|c|}
\hline \multirow[t]{4}{*}{ Left mid superficial femoral } & \multirow[t]{2}{*}{ No } & $f$ & 112 & 144 & 256 & \multirow[t]{4}{*}{$30.13^{* *}$} & \multirow[t]{4}{*}{0.00} \\
\hline & & $\%$ & 43.8 & 56.2 & 100.0 & & \\
\hline & \multirow[t]{2}{*}{ Yes } & $f$ & 24 & 120 & 144 & & \\
\hline & & $\%$ & 16.7 & 83.3 & 100.0 & & \\
\hline \multirow[t]{6}{*}{ Artery involvement } & \multirow{2}{*}{$\begin{array}{l}\text { No } \\
\text { involvement }\end{array}$} & $f$ & 52 & 16 & 68 & \multirow[t]{6}{*}{$66.98^{* *}$} & \multirow[t]{6}{*}{0.00} \\
\hline & & $\%$ & 76.5 & 23.5 & 100.0 & & \\
\hline & \multirow[t]{2}{*}{ Unilateral } & f & 60 & 160 & 220 & & \\
\hline & & $\%$ & 27.3 & 72.7 & 100.0 & & \\
\hline & \multirow[t]{2}{*}{ Bilateral } & $f$ & 24 & 88 & 112 & & \\
\hline & & $\%$ & 21.4 & 78.6 & 100.0 & & \\
\hline
\end{tabular}

Table 3: The prediction of presence of CAD with involvement of SFA among diabetics and non-diabetics.

\begin{tabular}{|c|c|c|c|c|c|}
\hline & & & \multicolumn{2}{|c|}{ Diabetes } & \multirow[t]{2}{*}{ Total } \\
\hline & & & No & Yes & \\
\hline \multirow[t]{10}{*}{ Coronary artery involvement } & \multirow[t]{2}{*}{ Left main disease } & $f$ & $18 \mathrm{a}_{\mathrm{a}}$ & $62_{b}$ & 80 \\
\hline & & $\%$ & $22.5 \%$ & $77.5 \%$ & $100.0 \%$ \\
\hline & \multirow[t]{2}{*}{ Single coronary disease } & $f$ & $55_{a}$ & $111_{b}$ & 166 \\
\hline & & $\%$ & $33.1 \%$ & $66.9 \%$ & $100.0 \%$ \\
\hline & \multirow[t]{2}{*}{ Double coronary disease } & $f$ & $0_{a}$ & $16_{b}$ & 16 \\
\hline & & $\%$ & $0.0 \%$ & $100.0 \%$ & $100.0 \%$ \\
\hline & \multirow[t]{2}{*}{ Triple coronary disease } & f & $0_{a}$ & 8 & 8 \\
\hline & & $\%$ & $0.0 \%$ & $100.0 \%$ & $100.0 \%$ \\
\hline & \multirow[t]{2}{*}{ Normal or mild coronary disease } & f & $71_{\mathrm{a}}$ & $59_{b}$ & 130 \\
\hline & & $\%$ & $54.6 \%$ & $45.4 \%$ & $100.0 \%$ \\
\hline \multirow{2}{*}{\multicolumn{2}{|c|}{ Total }} & $f$ & 144 & 256 & 400 \\
\hline & & $\%$ & $36.0 \%$ & $64.0 \%$ & $100.0 \%$ \\
\hline \multicolumn{2}{|c|}{ Chi-Square $=39.973 ; \mathrm{df}=4 ; \mathrm{p}<0.001$} & & & & \\
\hline
\end{tabular}

In Table 3, the prediction of presence of CAD with involvement of superficial femoral artery among diabetics and non-diabetics was shown. The relationship among the existence of the diabetes and coronary artery involvement in superficial femoral artery disease was statistically significant. The diabetic patients with superficial artery involvement suffered more from left main disease, single coronary disease, double coronary disease triple coronary disease than non-diabetic patients.

The decision tree made using the Chi-Square Automatic Interaction Detection (CHAID) method showed relationship between peripheral segmental region and CAD. Both right superficial femoral artery and left superficial femoral artery involvement increase the possibility of CAD by $88 \%$.

CHAID analysis showed coronary involvement region and peripheral arterial region. In coronary involvement investigation, $29 \%$ of the patients had LAD proximal lesion, and $18 \%$ of the patients had left main coronary or equivalent lesion. In coronary involvement, the most power predictor was mid superficial femoral artery disease. The presence of unaffected mid-left superficial femoral artery and mid-right superficial femoral artery showed the possibility of normal coronary disease by $63.3 \%$, but the involvement of both the mid-left superficial femoral artery and mid-right superficial femoral artery increased the possibility of left main coronary artery disease by $42.1 \%$.

The prediction model using cardiovascular risk factors and site of involvement of lower limb vessels was shown in Figure 1.

\section{Discussion}

Atherosclerosis may simultaneously affect several arterial regions, which is a progressive condition [1]. The prevalence of atherosclerosis-related PAD increasingly increases with age. Khoury, et al. [9] claimed that femoral atherosclerosis was a little bit prominent predictor of CAD than carotid atherosclerosis. Several studies reported that the CAD in patients with PAD occurred highly variable, ranging from 46 to $71 \%[5,6]$. This irregularity may be due to the variation among the definitions of CAD (i.e., $\geq 50 \%$ or $\geq 70 \%$ luminal narrowing) in diagnostic test, and regions of PAD (i.e., lower extremity, abdominal aorta, carotid artery, or renal artery) [9]. The patients with symptomatic lower limb PAD without cardiac symptoms had coronary atherosclerosis at $68 \%$ rate and $55 \%$ of those patients had significant $\geq 70 \%$ narrowing in coronary artery 


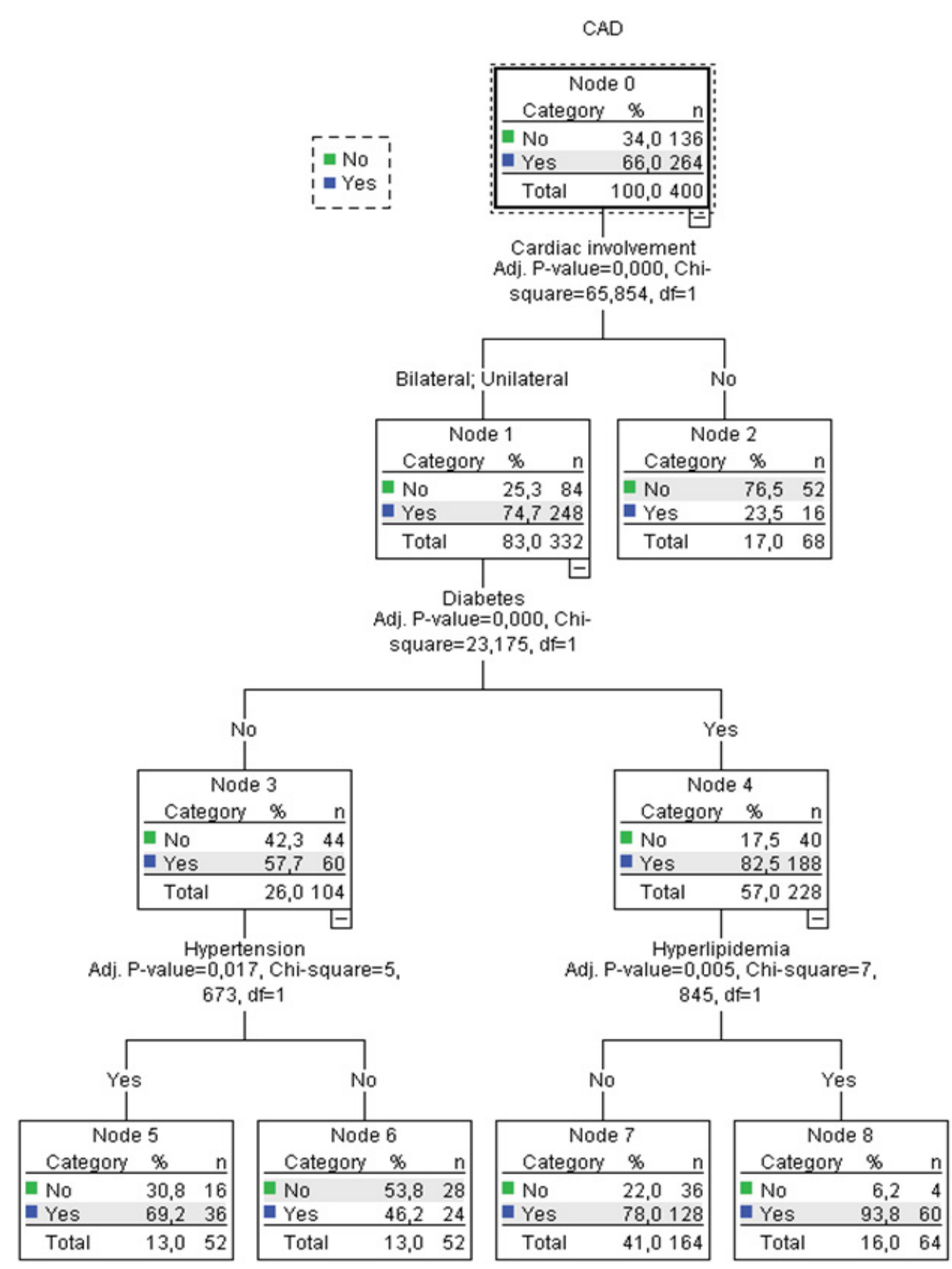

Figure 1: The prediction model using CV risk factors risk factors and site of involvement of lower limb vessels.

[10]. Our study findings indicate that the prevalence of CAD confirmed by coronary angiography in patients with PAD was higher than expected, although most of the patients had no cardiac symptoms. In our study, $66 \%$ of the patients without cardiac symptoms had concomitant CAD. An increased ratio of CAD possibility and early recognition of CAD in PAD may be, therefore, critical to improve the prognosis of PAD patients.

The most common risk factors connected with occurrence clinically significant PAD in men are type 2 diabetes mellitus, smoking, hypertension, and hypercholesterolemia [11]. The other aspect of management in these patients is related to their increased risk of any cardiovascular event [12]. Numerous studies have demonstrated which risk factor can foresee the concomitance of CAD in PAD patients. Cho, et al. [13] claimed that only independent predictor of concomitant multi-vessel disease diabetes was the diabetes, whereas Yilmaz, et al. [14] found that independent predictors of severe CAD in PAD patients were age, metabolic syndrome, and diabetes. In our study, diabetes mellitus had a statistically important effect on CAD $(p<0.01)$, and the existence of hypertension and hyperlipidemia had a important effect on the development of CAD $(p<0.05)$.

According to TASC II, the location of a PAD lesion affects the treatment choice and prognosis in patients with lower extremity PAD [4]. In this point, we created risk index to CAD by using each segment of the affected lower extremity arteries. We found that the prevalence of CAD was more in the femoral arteries involvement. Among the regions of the femoral arteries, superficial femoral arteries were affected more than the others. Interestingly, atherosclerosis of the femoropopliteal artery is characterized by high incidence of progression to occlusion, a propensity for superimposed calcification, 
and a large plaque burden $[15,16]$. Moreover, it has been known that superficial femoral artery has trended to de novo atherosclerosis. Moreover, initial atherosclerotic lesions have been more frequently seen in adductor hiatus of superficial femoral artery (midsuperficial artery) $[17,18]$. In light of these reality, we suggest that the most power predictor of the coronary involvement was mid superficial femoral artery disease. The presence of unaffected mid-left superficial femoral artery and mid-right superficial femoral artery showed the possibility of normal coronary disease by $63.3 \%$, though the involvement of both the mid-left superficial femoral artery and mid-right superficial femoral artery increased the possibility of left main coronary artery disease by $42.1 \%$. The presence of diabetes mellitus in the patients with unilateral or bilateral involvement of superficial femoral artery had important effect on the development of CAD as well. The diabetic patients with superficial artery involvement have suffered more from left main disease, single coronary disease, double coronary disease triple coronary disease than from nondiabetic patients.

Limitations:This study was performed retrospectively at a single center.

\section{Conclusion}

Our study results showed a high prevalence of asymptomatic CAD in patients with lower extremity $P A D$. The diabetes mellitus has a significant effect on CAD development among PAD patients. Both superficial femoral artery involvement increased the possibility of CAD. Moreover, the most power predictor of the coronary involvement was mid superficial femoral artery disease. Therefore, diabetic patients with midsuperficial femoral artery involvement should be assessed for severe CAD.

\section{Ethics Approval and Informed Consent}

Medicana International Ankara Hospital Ethics Committee accepted the study schedule [Numbered: 2017/2]. The study protocol was carried out in accordance with the Declaration of Helsinki.

\section{Data Availability (where applicable)}

The data will not be shared. Due to restrictions from Medicana International Ankara Hospital, the data are available upon request for any researcher based on a standard agreement on data provision.

\section{Consent for Publication}

Written informed consent for publication of their clinical details was obtained from the patient/parent/ guardian/relative of the patient.

\section{Disclaimer}

None.

\section{Conflict of Interests}

None.

\section{Source of Funding}

None.

\section{Author's Contributions}

Yasemin Saglamand Ersin Saricam contributed equally to this work as conception, study design, execution, and acquisition of data, analysis and interpretation; Yasemin Saglam and Ersin Saricam reviewed the article; Yasemin Saglam and Ersin Saricam agreed on the journal to which the article will be submitted; Yasemin Saglam and Ersin Saricam reviewed and agreed on all versions of the article before submission, during revision, the final version accepted for publication, and any significant changes introduced at the proofing stage; Yasemin Saglam and Ersin Saricam agree to take responsibility and be accountable for the contents of the article.

\section{Acknowledgments}

The authors acknowledge the logistic help and support by Bulent Altunkaynak, Professor, Statistician, Gazi University, Ankara.

\section{References}

1. Ross R (1999) Atherosclerosis: An inflammatory disease. $N$ Engl J Med 340: 115-126.

2. Golomb BA, Dang TT, Criqui MH (2006) Peripheral arterial disease: Morbidity and mortality implications. Circulation 114: 688-699.

3. Hansen ME, Valentine RJ, McIntire DD, Myers SI, Chervu A, et al. (1995) Age-related differences in the distribution of peripheral atherosclerosis: When is atherosclerosis truly premature? Surgery 118: 834-839.

4. Norgren L, Hiatt WR, Dormandy JA, Nehler MR, Harris KA, et al. (2007) TASC II Working Group. Inter-society consensus for the management of peripheral arterial disease. Int Angiol 26: 81-157.

5. Sukhija R, Aronow WS, Yalamanchili K, Sinha N, Babu $S$ (2004) Prevalence of coronary artery disease, lower extremity peripheral arterial disease, and cerebrovascular disease in 110 men with an abdominal aortic aneurysm. Am J Cardiol 94: 1358-1359.

6. Dieter RS, Tomasson J, Gudjonsson T, Brown RL, Vitcenda $M$, et al. (2003) Lower extremity peripheral arterial disease in hospitalized patients with coronary artery disease. Vasc Med 8: 233-236.

7. Sharma S, Thapa R, Jeevanantham V, Myers T, Hu C, et al. (2014) Comparison of lipid management in patients with coronary versus peripheral arterial disease. Am J Cardiol 113: $1320-1325$.

8. Mills JL Sr, Conte MS, Armstrong DG, Pomposelli FB, Schanzer A, et al. (2014) The society for vascular surgery lower extremity threatened limb classification system: Risk stratification based on wound, ischemia, and foot infection (WIfI). J Vasc Surg 59: 220-234.

9. Khoury Z, Schwartz R, Gottlieb S, Chenzbraun A, Stern $S$, et al. (1997) Relation of coronary artery disease to 
atherosclerotic disease in the aorta, carotid, and femora arteries evaluated by ultrasound. Am J Cardiol 80: 14291433.

10. Hur DJ, Kizilgul M, Aung WW, Roussillon KC, Keeley EC (2012) Frequency of coronary artery disease in patients undergoing peripheral artery disease surgery. Am J Cardiol 110: 736-740.

11. Joosten MM, Pai JK, Bertoia ML, Rimm EB, Spiegelman $D$, et al. (2012) Associations between conventional cardiovascular risk factors and risk of peripheral artery disease in men. JAMA 308: 1660-1667.

12. Aboyans V, Ricco JB, Bartelink MEL, Björck M, Brodmann M, et al. (2018) 2017 ESC Guidelines on the diagnosis and treatment of peripheral arterial diseases, in collaboration with the European Society for Vascular Surgery (ESVS): Document covering atherosclerotic disease of extracranial carotid and vertebral, mesenteric, renal, upper and lower extremity arteries endorsed by: The European Stroke Organization (ESO) the task force for the diagnosis and treatment of peripheral arterial diseases of the European Society of Cardiology (ESC) and of the European Society for Vascular Surgery (ESVS). Eur Heart J 39: 763-816.
13. Cho SW, Kim BG, Kim DH, Kim BO, Byun YS, et al. (2015) Prediction of coronary artery disease in patients with lower extremity peripheral artery disease. Int Heart J 56: 209-212.

14. Yilmaz MB, Guray Y, Guray U, Biyikoglu SF, Tandogan I, et al. (2006) Metabolic syndrome increases the risk of significant coronary artery involvement in patients with peripheral artery disease. Coron Artery Dis 17: 529-532.

15. Walsh DB, Powell RJ, Stukel TA, Henderson EL, Cronenwett JL (1997) Superficial femoral artery stenosis: Characteristics of progressing lesions. J Vasc Surg 25: 512-521.

16. Whyman MR, Ruckley CV, Fowkes FG (1993) A prospective study of the natural history of femoropopliteal artery stenosis using duplex ultrasound. Eur J Vasc Surg 7: 444-447.

17. Ansari F, Pack LK, Brooks SS, Morrison TM (2013) Design considerations for studies of the biomechanical environment of the femoropopliteal arteries. J Vasc Surg 58: 804-813.

18. Banerjee $S$ (2016) Superficial femoral artery is not left anterior descending artery. Circulation 134: 901-903. 